\title{
Classification of Parkinson Disease Based on Analysis and Synthesis of Voice Signal
}

\author{
Vikas Mittal, National Institute of Technology, Kurukshetra, India
}

R. K. Sharma, National Institute of Technology, Kurukshetra, India

\begin{abstract}
The most important application of voice profiling is pathological voice detection. Parkinson's disease is a chronic neurological degenerative disease affecting the central nervous system responsible for essentially progressive evolution movement disorders. Seventy to ninety percent of Parkinson's disease (PD) patients show an affected voice. This paper proposes a methodology for PD based on acoustic, glottal, physical, and electrical parameters. The results show that the acoustic parameter is more important in the case of Parkinson's disease as compared to glottal and physical parameters. The authors achieved $97.2 \%$ accuracy to differentiate Parkinson and healthy voice using jitter to pitch ratio proposed algorithm. The authors also proposed an algorithm of poles calculation of the vocal tract to find formants of the vocal tract. Further, formants are used for finding the transfer function of vocal tract filter. In the end, the authors suggested parameters of the electrical vocal tract model are also changed in the case of PD voices.
\end{abstract}

\section{KEYWORDS}

Acoustic Parameters, Electrical Circuit, Glottal Parameters, Physical Parameters, Vocal Tract Filter

\section{INTRODUCTION}

In multiple aspects, neurodegenerative, psychiatric and developmental disorders will adversely impact humans at all levels. Not only will these illnesses adversely affect one's quality of life, but also shorten one's average life span. Importantly, mental disabilities are often followed by a progressive deterioration of mental and physical abilities, which can in turn lead to one becoming dependent upon public-private healthcare resources, one's family and/or extended social networks for life. A key contribution of this work is towards improving the overall standards of human life and wellbeing vis-à-vis ongoing societal interactions since early detection of these devastating diseases will lessen the impact of the adverse effects, allowing timely monitoring of the evolution of these diseases.

Parkinson disease (PD) is a neurodegenerative disorder affecting predominately dopamineproducing "dopaminergic" neurons (Singh, 2007). According to World Health Organization (WHO), PD currently has 0.351 Disability Adjusted Life Years (DALYs) (Braga, 2019). Moreover, rates of PD occurrence are now expected to grow with increased life expectancy. While no cure for PD has yet been found, the quality of life for infected patients may be significantly improved with early diagnosis and interventions (Lang, 1998). Today, we know that a decrease of dopamine producing cells in the brain causes PD, but the root cause of decrease in dopamine producing cells is still unknown. The decrease in these cells affects the role of the neural activities and results in PD (Ho, 1999). 
Typical indicators of PD consist of muscular inflexibility, resting shake, postural volatility and cognitive destruction (Ramaker, 2002). PD is most common characterized by quiet voice, heaviness, slow and monotonous expression, imprecise articulation, air shortage and voice tremor. Owing to a slow initiation, delays in responses can also be observed, which can also be followed by speech rushes. During the course of the disease, there is often a reduced rate of speech and reading (Martin,2016; Sachin, 2008). Speech and voice can be studied by voice analysis and by evaluating other parameters of speech and language, such as subtle variations in voice frequencies (jitter), voice cycle-to-cycle magnitude difference (shimmer), volume (amplitude), vocal cord opening pressure, and more. More specifically, individuals affected by PD tend to have shorter average phonation time, higher jitter and glow, lower pitch range and decreased phonation threshold pressure (Chenausky, 2011).

In this article, the detection of PD via acoustic, physical, glottal parameters, frequency response of vocal tract as well as its equivalent electrical parameters is explored. In order for IJHISI readers to better understand the proposed methodologies in the context of voice pathology and detection, we present first, a method for detection and classification of PD voice based on acoustic, glottal and physical parameters, then discuss a series of details of the circuit for vocal tract filter for PD voice classification, and finally, proposed equivalent electrical circuit of vocal tract to compute its electrical parameters. The varying values of these parameters have been successfully used to classify PD affected subjects.

The remainder of this paper is organized as follows. Section 2reviewsthe extant literature related to the detection of PD. Section 3details the speech database and the proposed study methodology used to explore PD detection. Section4 describes study results and practical implications of the findings. Finally, Section 5offers a summary of the key contributions of this work, highlights potential study limitations and provides insights into future work.

\section{LITERATURE REVIEW}

Over the years, increasing attention has been given to studying people suffering from PD on the basis of voice and speech patterns (Rusz, 2015; Saxena, 2014). To date, about 90\% of PD patients are projected to suffer speech related problems (Little, 2009). Rouzbahani \& Daliri (2011) defined a technique to diagnose PD in humans using voice signals. Saloni, et al. (2016) had proposed classifying PD via local angular frequency and instantaneous deviation in the waveform. In advance-stage PD, the voice is often neither audible nor intelligible, thereby leading to deterioration in the functioning of vocal folds. To identify the effects of speech and voice disorders in PD, there are many speaking exercises that could be used. Sustained phonation, freely spoken spontaneous expression are the most traditional of these (Mittal, 2020).

It is estimated that a PD patient would have some type of speech and language impairment (Robin, 2015). Significant differences of speech can be affected, such as spoken language production (dysprosody), voice production (dysphony), and articulation (dysarthria) (e.g., Galaz, 2016; Pawlukowska, 2015;Lirani-Silva, 2015;Sapir, 2014).Recent research has also made great progress in speech-based measures for PD, producing interesting results due to the non-invasive nature of the methods. Polat, et al. (2020),presented a novel data sampling approach for the classification of PD based on the acoustic characteristics of speech signals. Some changes in vocal cords have been described in Parkinson's associated hypokinetic dysarthria, which can be observed by direct laryngoscopy (Blumin, 2004).

Prior research has focused on emerging approaches in the detection of PD. Several studies on the prediction and classification of Parkinson's disease via different approaches have been reviewed herein. A recent simple approach based on handwriting from people with PD has been advanced in (Gupta, et al.,2020). The combination of empirical mode decomposition and neural network (NN) method used for Parkinson's disease classification has also been advocated (e.g., Zeng, et al, .2019). 
Tsanas et al. (2011) proposed the Relief and Local Learning-Base Feature Selection (LLBFS) techniques for the detection of PD.

Other classification algorithms and smart methods have also been suggested, for example, some researchers have argued the use of prediction support tools for PD classification (e.g., Affonso, 2017; Hrelja, 2013; Ficko,2010), but accurate predictions can only be made to a certain degree (Liu,2015). $\mathrm{Alku}$ (2011)discussed the idea of Glottal inverse filtering (GIF) for use infitting a model for the vocal tract filter, resulting in an estimate of the glottal flow signal. (Drugman, 2012; Sakar, et al. 2013) examined various kinds of sound recordings obtained from people with PD. The extracted features have been fed into Support Vector Machine (SVM) and k-Nearest Neighbor (k-NN) classifiers for PD diagnosis via a leave-one-subject-out (LOSO) cross-validation scheme and summarized LeaveOne-Out.Also, several experiments on voice recordings were originally conducted at the University of Oxford (Little,2009). Shahbakhi, et al. (2014) presented the best PD classification results at 94.50\% accuracy. A method for acoustical analysis of PD speech, the classification of the extent of speech impairment with the aim of improving speech therapy success rates described by (Baasch, et al.,2016)

Some published work using Random Forest (RF) algorithm to detect PD can also be found. Vaiciukynas, et al. (2017) recommended a technique for detecting PD using RF from sustained phonations. The possibility of combining the Multi-Edit-Nearest-Neighbor (MENN) and RF techniques to identify PD was discussed by Zhang, et al. (2016). To develop a classification model, Caglar, et al. (2009) used Machine Learning Programming (MLP). The supervised learning algorithm focused at separating massive amounts of data using the hyper plane and margin concept described by (Sewell, 2017).

Another body of research work discussed the detection of healthy and pathological voices via the electrical modeling of the vocal tract (Mittal, 2019). Wee, et al. (2008) presented the first experimental integrated-circuit vocal tract can be used to generate speech. Wee, et al.(2011) described an integrated-circuit vocal tract to create speech-locked loop. A two-mass model characterizing the properties of vocal folds was explored by Yao (2013). For the classification of normal and stressed voice, he used the vocal tract to simulate speech production. Dixit (2014) examined the variations between PD patients v. normal subjects using Praat as the software for extracting features from the voice signal, taking into consideration the voice parameter analysis.

With the overall goal to detect PD via voice analysis, this study investigates the detection of PD via acoustic, physical, glottal parameters, frequency response of vocal tract as well as its equivalent electrical parameters.

\section{MATERIALS AND METHOD}

\subsection{Sampling}

The dataset used in this work was drawn fromKing's College London (KCL) Hospital, Denmark Hill, Brixton, London SE5 9RS. KCL used a typical examination room with about ten (10) square meters area and a typical reverberation time of approximately $500 \mathrm{~ms}$ to perform the voice recordings.

The dataset comprises phonation from 16 Parkinson and 21 control subjects. The samples were recorded with Motorola Moto G4 Smartphone using "Toggle Recording App". The recordings were done by test executor at a sampling frequency of $44.1 \mathrm{KHz}$ with 16 bit resolution of spontaneous dialog with the participants. The test executor starts asking random questions about places of interest, local traffic, or personal interests, where and if acceptable. For each normal v. PD participant, the voice recordings are labeled in the following format:

\section{SI_HS_HYR_UPDRS II-5_UPDRS III-18}

Where: 


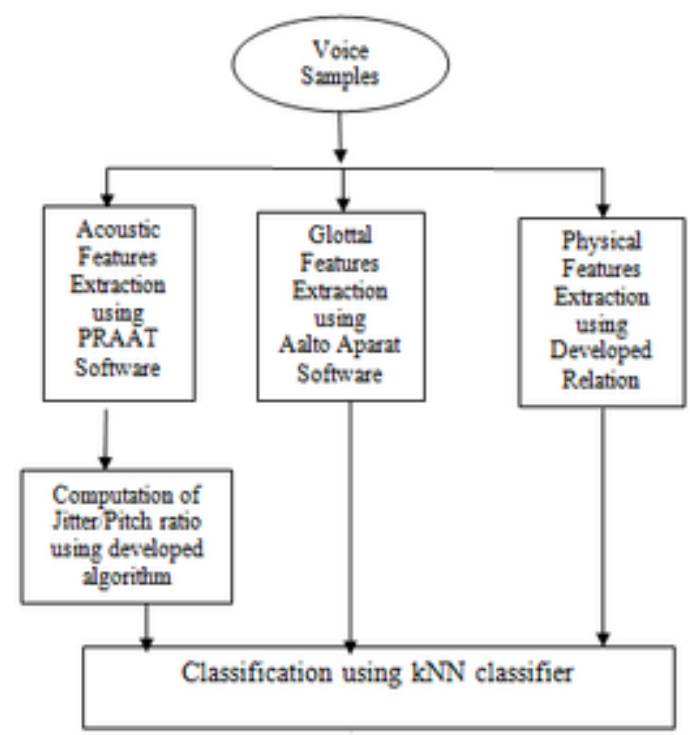

- $\quad$ SI is subject identification in the form IDNN, $N$ in $[0,9]$

- $\quad H S$ is the health status label (Normal or PD accordingly)

- HYR is the expert assessed H\&Y scale rating

- UPDRS II-5 is according to expert peer-reviewed score

- UPDRS III-18 is the according expert assessed score

\subsection{Method}

Figure 1 shows the proposed methodology used for PD detection.

Parameters used in proposed methodology are briefly described below.

\subsubsection{Acoustic Parameters:}

- Pitch: In phonetics, the "pitch" is the frequency (or harmonic height) of the lowest tone wave in voice (Forero Mendoza, 2014).

- Jitter: The cycle-to-cycle variance of the basic frequency, that is, the average absolute difference between successive cycles, express as a jitter(Forero Mendoza,2014).

$$
\text { Jitter }=\frac{1}{N-1} \sum_{i=1}^{N-1}\left|T_{i}-T_{i+1}\right|
$$

where, Ti is the $\mathrm{i}^{\text {th }}$ extracted $\mathrm{F}_{0}$ period length and $\mathrm{N}$ is the number of extracted $\mathrm{F}_{0}$ periods.

- Shimmer: Variability in decibels $(\mathrm{dB})$ of peak-to-peak amplitude. The process used to evaluate the shimmer is similar to jitter, the only difference being that the jitter takes into account intervals and shimmer takes into account the full signal amplitude (Forero Mendoza,2014). 


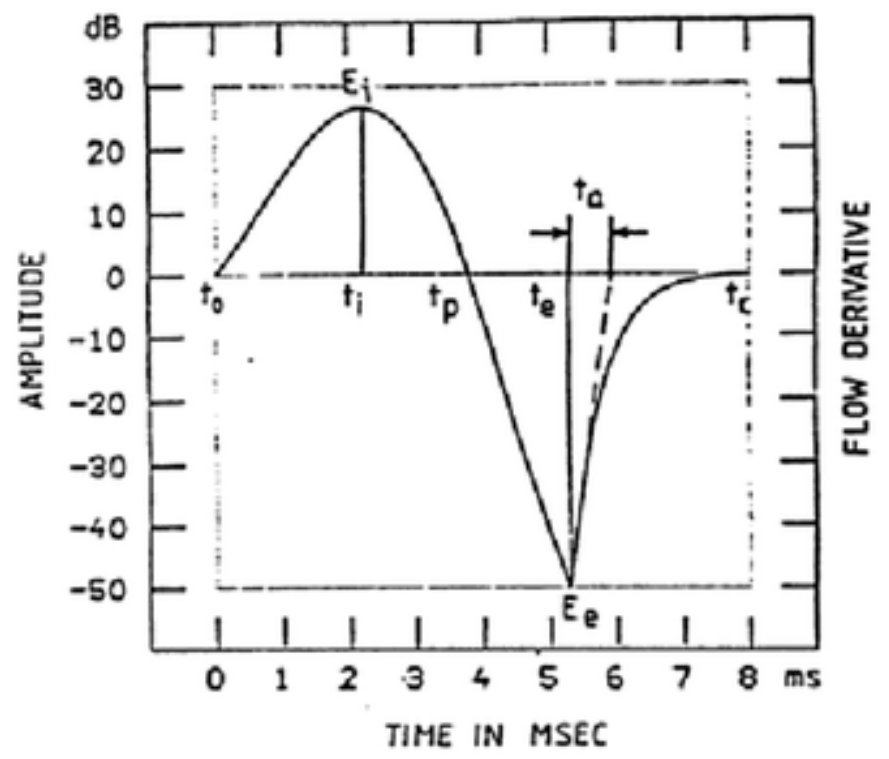

Shimmer (local, dB): $=\frac{1}{N-1} \sum_{i=1}^{N-1} 20 * \log \left(\frac{A_{i+1}}{A_{i}}\right)$

where, $\mathrm{A}_{\mathrm{i}}$ is the $\mathrm{i}^{\text {th }}$ extracted $\mathrm{F}_{0}$ period amplitude.

- Jitter to Pitch Ratio (JPR): It is defined as ratio of Jitter to the Pitch of voice signal.

\subsubsection{Glottal Parameters:}

The QOQ and NAQ are often selected as the glottal parameters as they are robust to measuring noise and do not require the difficult task of estimating the glottal opening moment (Fant, 1985).

- $\quad$ Normalized Amplitude Quotient(NAQ): The NAQ is computed as:

$$
\mathrm{NAQ}=\frac{\mathrm{AQ}}{\mathrm{T}}
$$

- Quasi Opening Quotient $(Q O Q)$ :This is defined as the time interval during which the glottal flow is $50 \%$ above the minimum flow.

- L-F model Parameters: The LF model is used to represent the glottal flow derivative (GFD) (Finkelhor,1988).

Typically, the four parameters are three time points $\mathbf{t}_{\mathbf{e}}, \mathbf{t}_{\mathbf{p}}, \mathbf{t}_{\mathbf{e}}$ and one amplitude parameter $\mathbf{E}_{\mathbf{e}}$. As shown in Figure 2, $\mathbf{t}_{\mathbf{e}}$ is the glottal closing instant, $\mathbf{t}_{\mathbf{a}}$ is related to return phase, $\mathbf{t p}$ is positive peak of glottal flow and $\mathbf{E}_{\mathbf{e}}$ is negative peak of derivative function. 


\subsubsection{Physical Parameters:}

- $\quad$ Stiffness $(\boldsymbol{k})$ :

Stiffness is related to muscle tension and fundamental frequency. In the Ishizaka-Flanagan (1972) model, the standard value of $\mathrm{m}_{1}$ can be considered to be equal to $0.125 \mathrm{~g}$.Moreover,Dejonckere(1984) relates $\mathrm{m}_{1} \& \mathrm{~m}_{2}$ and $\mathrm{k}_{1} \& \mathrm{k}_{2}$ as:

$\mathrm{m}_{2}=\frac{\mathrm{m}_{1}}{5}$ and $\mathrm{k}_{2}=\frac{\mathrm{k}_{1}}{10}$

where, $\mathbf{k}_{\mathbf{1}}$ is lower spring stiffness and $\mathbf{m}_{\mathbf{1}}$ is lower mass. Similarly, $\mathbf{k}_{\mathbf{2}}$ is upper spring stiffness and $\mathbf{m}_{\mathbf{2}}$ is upper mass.

$\mathrm{F}_{0}$, as a function of $\mathbf{k}$ and $\mathbf{m}$ can be defined as:

$\mathrm{F}_{0}=\frac{1}{2 \grave{A}} \sqrt{\frac{\mathrm{k}}{\mathrm{m}}}$

where $\mathrm{k}=\mathrm{k}_{1}+\mathrm{k}_{2}$ and $\mathrm{m}=\mathrm{m}_{1}+\mathrm{m}_{2}$. Consequently, $\mathrm{F}_{0}$ reduces to:

$\mathrm{F}_{0}=\frac{1}{2 \grave{A}} \sqrt{\frac{1.1 \mathrm{k}_{1}}{1.2 \mathrm{~m}_{1}}}$

From equation (6), $\mathrm{k}_{1}$ may be computed as:

$\mathrm{k}_{1}=\frac{(\mathrm{F} 0 * 2 \grave{\mathrm{A}})^{2} *\left(1.2 \mathrm{~m}_{1}\right)}{1.1}$

- Viscosity:

Viscosity of vocal foldsmay be calculated as[38]:

$r_{1}=2 \zeta_{1} \sqrt{m_{1} \mathrm{k} 1} r_{2}=2 \zeta_{2} \sqrt{m_{2} k_{2}}$

where $\zeta_{1}, \zeta_{2}$ refer to damping ratios for the viscous resistances $r_{1}$ and $r_{2}$.

\subsubsection{Classifier}

Largely based on similarity feature, the kNN classifier is used for classification. Put simply, this classifier checks how similar any data point is to its neighboring data points, and it then classifies the objects automatically based on the principal of the computed minimum distance to the centroid (Agarwal, 2016). 


\section{RESULTS AND IMPLICATIONS}

The acoustic, glottal and physical parameters results for every normal v. PD subject have been computed and provided in Table 1. In the case of a PD person's voices, it has been observed that the comparative values of pitch and the fundamental frequency are smaller whereas the jitter and shimmer values are bigger. The roughness in the voice is increased due to the increase in jitter in PD persons. An increase in shimmer means an increase in the amplitude of signal with increase inthe voice perturbation, resulting in a less clear voice in the case of PD.

\section{Table 1. Computed values of Acoustic Parameters}

\begin{tabular}{|c|c|c|c|c|c|c|c|}
\hline \multicolumn{4}{|c|}{ Normal Subjects } & \multicolumn{4}{|c|}{ Parkinson(PD) Subjects } \\
\hline $\begin{array}{c}\text { Pitch } \\
(\mathbf{H z})\end{array}$ & $\begin{array}{c}\text { Jitter } \\
(\%)\end{array}$ & $\begin{array}{l}\text { Shimmer } \\
\text { (dB) }\end{array}$ & $\begin{array}{c}\text { (Jitter/Pitch) } \\
\text { Ratio }\end{array}$ & $\begin{array}{c}\text { Pitch } \\
(\mathbf{H z})\end{array}$ & $\begin{array}{c}\text { Jitter } \\
(\%)\end{array}$ & $\begin{array}{l}\text { Shimmer } \\
\text { (dB) }\end{array}$ & $\begin{array}{c}\text { (Jitter/Pitch) } \\
\text { Ratio }\end{array}$ \\
\hline 217.3 & 1.42 & 0.67 & 0.65 & 154.6 & 3.73 & 1.44 & 2.42 \\
\hline 217.9 & 2.59 & 0.95 & 1.19 & 157.8 & 3.21 & 1.66 & 2.04 \\
\hline 211.7 & 1.57 & 0.75 & 0.74 & 179.7 & 2.70 & 1.46 & 1.5 \\
\hline 183.9 & 1.98 & 0.85 & 1.08 & 176.4 & 4.44 & 1.62 & 2.52 \\
\hline 204.4 & 1.56 & 0.74 & 0.76 & 160.2 & 2.80 & 1.11 & 1.75 \\
\hline 183.2 & 2.12 & 0.84 & 1.15 & 174.5 & 2.76 & 1.42 & 1.58 \\
\hline 207.8 & 2.67 & 0.96 & 1.28 & 165.3 & 2.74 & 1.14 & 1.66 \\
\hline 275.4 & 2.67 & 1.27 & 0.97 & 148.2 & 2.95 & 0.84 & 1.99 \\
\hline 266.0 & 2.69 & 1.08 & 1.01 & 141.0 & 2.84 & 1.02 & 2.01 \\
\hline 263.8 & 2.72 & 1.36 & 1.03 & 196.0 & 3.36 & 1.38 & 1.71 \\
\hline 214.6 & 2.02 & 1.26 & 0.94 & 225.7 & 3.79 & 1.63 & 1.68 \\
\hline 186.4 & 2.71 & 1.06 & 1.45 & 226.4 & 3.85 & 1.75 & 1.70 \\
\hline 187.9 & 1.65 & 0.77 & 0.88 & 179.2 & 3.37 & 0.97 & 1.88 \\
\hline 189.8 & 2.60 & 0.96 & 1.37 & 177.5 & 3.05 & 1.12 & 2.07 \\
\hline 195.4 & 1.52 & 0.78 & 0.77 & 147.6 & 3.43 & 1.64 & 2.33 \\
\hline 189.4 & 1.51 & 0.83 & 0.79 & & & & \\
\hline 191.5 & 2.59 & 0.71 & 1.35 & & & & \\
\hline 260.2 & 2.93 & 1.18 & 1.12 & & & & \\
\hline 254.4 & 1.96 & 0.83 & 0.77 & & & & \\
\hline 283.4 & 2.81 & 0.58 & 0.99 & & & & \\
\hline 395.8 & 2.52 & 0.62 & 0.63 & & & & \\
\hline
\end{tabular}

As shown in Table 2 and Figure 3, mean values of shimmer and jitter tend to be bigger with the pitch being smaller in case of PD group. Table 2 depicts the mean and standard deviation values of the acoustic parameters. The standard deviation value of shimmer is greater while thepitch and jitter are smaller in the case of the PD group.

Figure 3 shows the bar graph of mean $(\boldsymbol{\mu})$ and standard deviation $(\boldsymbol{\sigma})$ values of each acoustic parameter. 
Table 2. Mean and Standard Deviation of Acoustic Parameters

\begin{tabular}{|c|c|c|c|c|}
\hline \multirow{2}{*}{ Acoustic Parameters } & \multicolumn{2}{|c|}{ Normal } & \multicolumn{2}{|c|}{ PD } \\
\cline { 2 - 5 } & Mean $(\boldsymbol{\mu})$ & $\begin{array}{c}\text { Standard deviation } \\
(\boldsymbol{\sigma})\end{array}$ & Mean $(\boldsymbol{\mu})$ & $\begin{array}{c}\text { Standard deviation } \\
(\boldsymbol{\sigma})\end{array}$ \\
\hline Pitch & 227.6 & 51.09 & 174.04 & 25.8 \\
\hline Jitter & 2.23 & 0.522 & 3.27 & 0.51 \\
\hline Shimmer & 0.91 & 0.22 & 1.35 & 0.29 \\
\hline
\end{tabular}

Figure 3. Mean $(\mu)$ and Standard deviation $(\sigma)$ of acoustic parameters

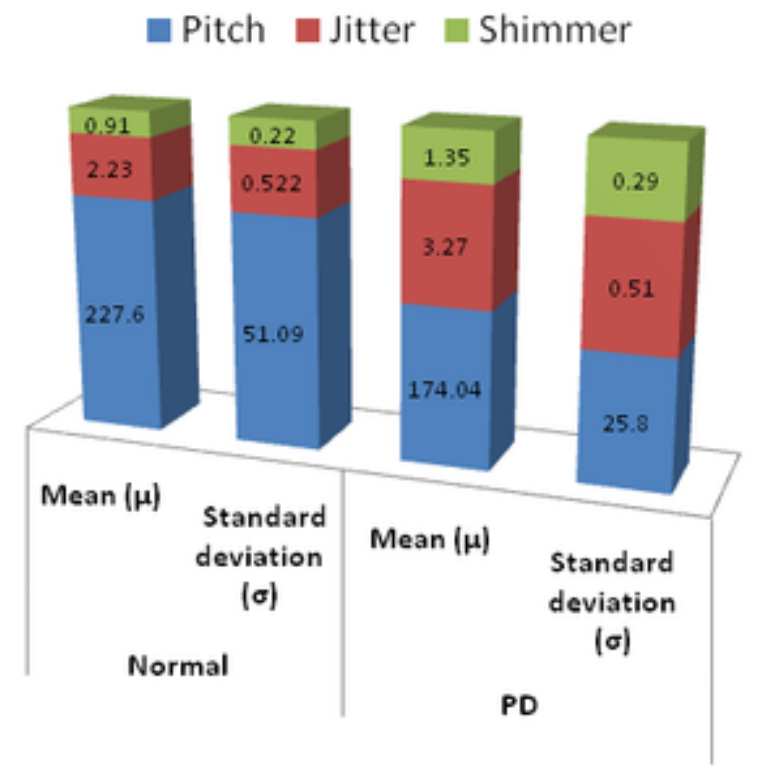

NAQ is an estimation of the duration of the glottal closing phase. It is the most effective measure for describing voice qualities. Table 3 shows the variations of glottal parameters for normal v. PD subjects' voices.In the case of PD subjects, values of NAQ are higher.

An increased NAQ indicates a breathy phonation. The variation in the values of Quasi Opening Quotient (QOQ) quantify the glottal cycle in the case of normal v. PD subjects. In the case of PD subjects, the positive peak time $\left(\mathrm{T}_{\mathrm{p}}\right)$ of glottal wave is large and changes the period of glottal wave. The glottal closing time $\left(\mathrm{T}_{\mathrm{e}}\right)$ is increased in the voice of the PD subjects.

Table 4 represents the values of mean and standard deviation of glottal and LF parameters. As shown inFigure 4, in the case of PD subjects, the mean values of NAQ, QOQ, Tp and $T_{e}$ parameters and standard deviation of $\mathrm{T}_{\mathrm{p}}$ and $\mathrm{T}_{\mathrm{e}}$ increased; also, from Figure $\mathbf{4}$ and Table 4, it is apparent thatthe standard deviation of NAQ and QOQ decreased in the case of PD.

Table 5 shows the values of stiffness $\left(\mathbf{k}_{1}\right)$ and viscous resistance $\left(\mathbf{r}_{\mathbf{1}}\right)$ in voices of normal v. PD subjects. In the case of PD subjects, the values of stiffness $\left(\mathrm{k}_{1}\right)$ and viscous resistance $\left(\mathrm{r}_{1}\right)$ are smaller.

From Table 6 and Figure 5, it is apparent that the mean value of physical parameters is smaller while the standard deviation of physical parameters is bigger in the case of PD subjects. 
Table 3. Computed values of glottal parameters

\begin{tabular}{|c|c|c|c|c|c|c|c|}
\hline \multicolumn{4}{|c|}{ Normal Subjects } & \multicolumn{4}{|c|}{ Parkinson(PD) Subjects } \\
\hline NAQ & QOQ & $\mathbf{T}_{\mathrm{p}}(\mathbf{m s})$ & $\mathbf{T}_{\mathbf{e}}(\mathbf{m s})$ & NAQ & QOQ & $\mathbf{T}_{\mathrm{p}}(\mathbf{m s})$ & $\mathbf{T}_{\mathbf{e}}(\mathbf{m s})$ \\
\hline 0.08 & 0.17 & 0.89 & 2.53 & 0.18 & 0.45 & 5.53 & 7.58 \\
\hline 0.06 & 0.38 & 0.006 & 0.01 & 0.15 & 0.58 & 4.43 & 7.01 \\
\hline 0.11 & 0.23 & 2.17 & 3.36 & 0.08 & 0.28 & 8.05 & 14.8 \\
\hline 0.09 & 0.32 & 0.01 & 0.02 & 0.051 & 0.16 & 0.09 & 0.21 \\
\hline 0.07 & 0.29 & 2.28 & 5.01 & 0.09 & 0.49 & 1.45 & 3.39 \\
\hline 0.05 & 0.24 & 0.03 & 0.03 & 0.12 & 0.34 & 0.021 & 0.027 \\
\hline 0.02 & 0.09 & 0.01 & 0.04 & 0.11 & 0.45 & 0.09 & 0.12 \\
\hline 0.21 & 0.60 & 1.15 & 3.50 & 0.13 & 0.49 & 0.07 & 0.11 \\
\hline 0.07 & 0.31 & 2.79 & 3.86 & 0.23 & 0.58 & 3.61 & 7.81 \\
\hline 0.14 & 0.55 & 3.47 & 5.38 & 0.12 & 0.20 & 1.67 & 2.27 \\
\hline 0.14 & 0.42 & 4.94 & 7.15 & 0.17 & 0.49 & 4.72 & 7.00 \\
\hline 0.04 & 0.34 & 1.96 & 2.97 & 0.15 & 0.30 & 0.03 & 0.13 \\
\hline 0.07 & 0.39 & 3.18 & 4.44 & 0.10 & 0.40 & 0.04 & 0.06 \\
\hline 0.04 & 0.12 & 0.28 & 0.53 & 0.15 & 0.42 & 1.31 & 2.74 \\
\hline 0.07 & 0.17 & 3.86 & 4.86 & 0.08 & 0.49 & 2.54 & 3.88 \\
\hline 0.05 & 0.30 & 0.001 & 0.002 & & & & \\
\hline 0.06 & 0.22 & 0.04 & 0.05 & & & & \\
\hline 0.07 & 0.39 & 0.009 & 0.017 & & & & \\
\hline 0.21 & 0.40 & 1.25 & 3.40 & & & & \\
\hline 0.08 & 0.21 & 2.49 & 3.66 & & & & \\
\hline 0.12 & 0.45 & 3.37 & 3.38 & & & & \\
\hline
\end{tabular}

\section{Table 4. Mean and Standard Deviation of Time-based and LF-Model Glottal Parameters}

\begin{tabular}{|c|c|c|c|c|}
\hline \multirow{2}{*}{$\begin{array}{l}\text { Glottal Time-based and } \\
\text { LF-Model Parameters }\end{array}$} & \multicolumn{2}{|c|}{ Normal } & \multicolumn{2}{c|}{ PD } \\
\cline { 2 - 5 } & Mean $(\boldsymbol{\mu})$ & Standard deviation $(\boldsymbol{\sigma})$ & Mean $(\boldsymbol{\mu})$ & Standard deviation $(\boldsymbol{\sigma})$ \\
\hline NAQ & 0.09 & 0.05 & 0.13 & 0.04 \\
\hline QOQ & 0.13 & 0.31 & 0.41 & 0.12 \\
\hline $\mathrm{T}_{\mathrm{P}}$ & 1.63 & 1.56 & 2.24 & 2.50 \\
\hline $\mathrm{T}_{\mathrm{e}}$ & 2.16 & 2.58 & 3.81 & 4.29 \\
\hline
\end{tabular}

\subsection{Classification}

The aim of KNN classifying algorithm is to automatically distinguish normal v. PD subjects via discriminatory features derived from speech signals. In order to measure the performance of each parameter in distinguishing between normal v. PD speech signals, the receiver operating characteristic (ROC) and the area under curve (AUC) were used. 
Figure 4. Mean $(\mu)$ and Standard Deviation $(\sigma)$ of glottal parameters

$=\mathrm{NAQ}=\mathrm{QOQ}=\mathrm{TP}=\mathrm{Te}$

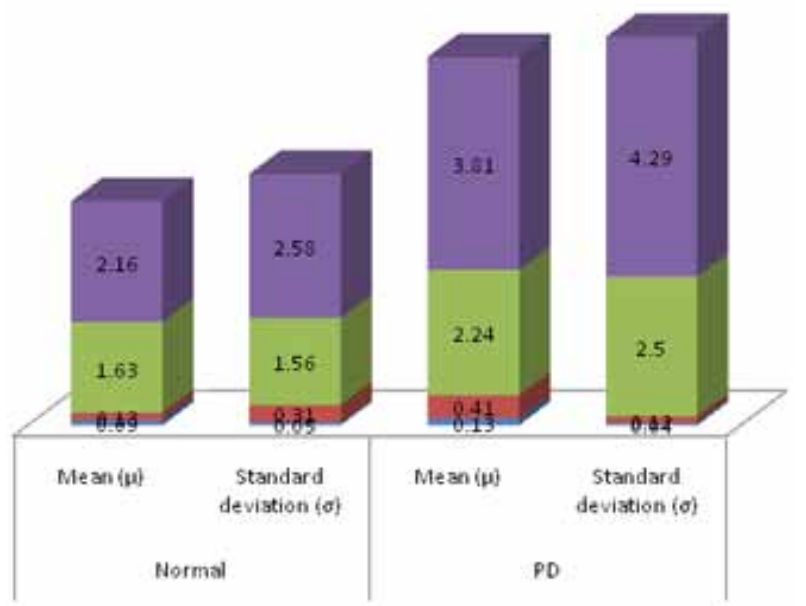

Table 5. Computed values of stiffness $\left(k_{1}\right)$ and viscous resistance $\left(r_{1}\right)$

\begin{tabular}{|c|c|c|c|c|c|}
\hline \multicolumn{3}{|c|}{ Normal Subjects } & \multicolumn{3}{|c|}{ Parkinson(PD) Subjects } \\
\hline $\begin{array}{c}\text { Fundamental } \\
\text { Frequency } \mathrm{F}_{\mathbf{0}}(\mathrm{Hz})\end{array}$ & $\begin{array}{c}\text { Stiffness }\left(\mathbf{k}_{1}\right) \\
(\mathbf{k d y n} / \mathbf{c m})\end{array}$ & $\begin{array}{c}\text { Viscous } \\
\text { Resistance }\left(\mathbf{r}_{1}\right) \\
\end{array}$ & $\begin{array}{c}\text { Fundamental } \\
\text { Frequency } \mathrm{F}_{0}(\mathrm{~Hz})\end{array}$ & $\begin{array}{c}\text { Stiffness }\left(\mathbf{k}_{\mathbf{1}}\right) \\
(\mathbf{k d y n} / \mathbf{c m})\end{array}$ & $\begin{array}{c}\text { Viscous } \\
\left.\text { Resistance ( } \mathbf{r}_{\mathbf{1}}\right) \\
\end{array}$ \\
\hline 180 & 174.2 & 0.93 & 91 & 44.5 & 0.47 \\
\hline 183 & 180.1 & 0.94 & 122 & 80 & 0.63 \\
\hline 118 & 74.8 & 0.61 & 62 & 20.6 & 0.32 \\
\hline 261 & 223.5 & 1.05 & 142 & 108.4 & 0.73 \\
\hline 141 & 106.9 & 0.73 & 251 & 338.8 & 1.3 \\
\hline 242 & 314.9 & 1.25 & 229 & 282 & 1.18 \\
\hline 267 & 383.3 & 1.38 & 180 & 174.2 & 0.93 \\
\hline 242 & 314.9 & 1.25 & 193 & 200.3 & 1 \\
\hline 178 & 170.3 & 0.92 & 116 & 72.3 & 0.6 \\
\hline 144 & 111.5 & 0.74 & 228 & 279.5 & 1.18 \\
\hline 127 & 86.7 & 0.65 & 121 & 78.7 & 0.62 \\
\hline 188 & 190 & 0.97 & 179 & 172.3 & 0.92 \\
\hline 136 & 99.4 & 0.70 & 228 & 279.5 & 1.18 \\
\hline 234 & 294.4 & 1.21 & 193 & 183.6 & 0.95 \\
\hline 73 & 28.6 & 0.37 & 213 & 243.9 & 1.10 \\
\hline 191 & 196.1 & 0.99 & & & \\
\hline 185 & 184 & 0.95 & & & \\
\hline 174 & 162.8 & 0.90 & & & \\
\hline 212 & 241.7 & 1.09 & & & \\
\hline 158 & 134.2 & 0.81 & & & \\
\hline 164 & 144.6 & 0.85 & & & \\
\hline
\end{tabular}


Table 6. Mean and Standard deviation of Physical Parameters

\begin{tabular}{|c|c|c|c|c|}
\hline \multirow{2}{*}{ Physical Parameters } & \multicolumn{2}{|c|}{ Normal } & \multicolumn{2}{c|}{ PD } \\
\cline { 2 - 5 } & Mean $(\boldsymbol{\mu})$ & Standard deviation $(\boldsymbol{\sigma})$ & Mean $(\boldsymbol{\mu})$ & Standard deviation $(\boldsymbol{\sigma})$ \\
\hline $\begin{array}{c}\text { Stiffness }\left(\mathrm{k}_{1}\right) \\
(\mathrm{kdyn} / \mathrm{cm})\end{array}$ & 181.7 & 89.3 & 170.5 & 99.8 \\
\hline Viscous Resistance $\left(\mathrm{r}_{1}\right)$ & 0.91 & 0.24 & 0.87 & 0.29 \\
\hline
\end{tabular}

Figure 5. Mean $(\mu)$ and Standard Deviation $(\sigma)$ of physical parameters

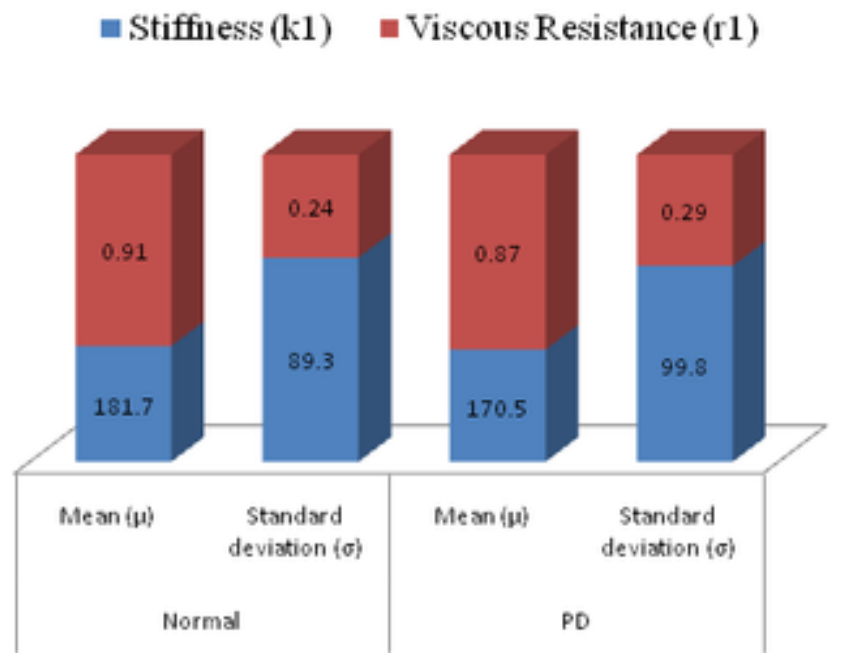

\subsubsection{The Receiver Operating Characteristic (ROC):}

In ROC, the false positive rate (FPR) indicates an incorrect observation by current classifier whereas the true positive rate (TPR) indicates the correct observation by the current classifier. As shown inTable7, the value of AUC is larger in case of acoustic parameters as compared to other parameters. Essentially, a larger AUC in acoustic parameters represents better performance for PD detection.

In order to test the classifier performance, sensitivity (SE), specificity (SP), the overall accuracy (AUC) and Matthews's correlation coefficient (MCC) are all measured (Aggarwal,2016) as follows:

Sensitivity $=\frac{T P}{T P+F N}$

Specificity $=\frac{T N}{T N+F P}$

Overall Accuracy $=\frac{(T P+T N)}{(T P+T N+F P+F N)}$

$\mathrm{MCC}=\frac{\left(T P^{*} T N\right)-\left(F P^{*} F N\right)}{\sqrt{(T P+F P)(T P+F N)(T N+F P)(T N+F N)}}$ 
Table 7. Computed values of AUC for different parameters

\begin{tabular}{|c|c|c|c|}
\hline Parameters & TPR & FPR & Area Under Curve(AUC) \\
\hline Acoustic & 0.95 & 0.07 & 0.93 \\
\hline Glottal & 0.71 & 0.40 & 0.60 \\
\hline Physical & 1 & 1 & 0.53 \\
\hline
\end{tabular}

MCC: Matthews's correlation coefficient is $\mathbf{1}$ for perfect prediction while $\mathbf{0}$ for extremely arbitrary prediction.

Table 8 shows the comparison of kNN classifier performance for acoustic, glottal and physical parameters. Result shows $97.2 \%$ accuracy with acoustic parameters.

The next subsections describe all pole and electrical modeling of vocal tract to differentiate between normal v. PD voices.

Table 8. Performance Analysis of kNN classifier

\begin{tabular}{|c|c|c|c|c|}
\hline Parameters & Sensitivity (SE) & Specificity (SP) & $\begin{array}{c}\text { Overall Accuracy } \\
\text { (AUC) in \% }\end{array}$ & MCC \\
\hline Acoustic & 0.95 & 0.93 & 97.2 & 0.88 \\
\hline Glottal & 0.71 & 0.70 & 66.7 & 0.31 \\
\hline Physical & 0.58 & 0 & 58.3 & 0 \\
\hline
\end{tabular}

\subsection{All Pole Modeling of Vocal Tract}

The acoustic tube model of vocal tract is all-pole (Ali, 2016). Using LPC modeling of the vocal tract filter, its transfer function is computed. Thereafter, with the help of the transfer function, the values of components of vocal tract filter circuit are further computed. Table 9 shows the computed values of transfer functions and formants for each normal v. PD subject.

\subsubsection{Circuit Design of vocal tract filter}

The transfer function of second order filter is given as:

$$
\mathrm{H}(\mathrm{s})=\frac{A}{s^{2}+\frac{\omega_{0}}{Q} s+\omega_{0}^{2}}
$$

The unity gain sallen-key low pass circuit shown in Figure 6.

The transfer function of the circuit is given by: 
Table 9. Computed values of formants and transfer function

\begin{tabular}{|c|c|c|c|c|c|c|c|}
\hline \multicolumn{4}{|c|}{ Normal Subjects } & \multicolumn{4}{|c|}{ Parkinson(PD) Subjects } \\
\hline F1 & F2 & $\mathbf{F 3}$ & Transfer Function H(s) & F1 & $\mathbf{F} 2$ & $\mathbf{F 3}$ & Transfer Function H(s) \\
\hline \multirow[b]{2}{*}{351} & \multirow[b]{2}{*}{9500} & \multirow{2}{*}{11420} & 1 & \multirow{2}{*}{4051} & \multirow{2}{*}{10400} & \multirow{2}{*}{12460} & 1 \\
\hline & & & $\overline{s^{2}+1.322 s+0.3367}$ & & & & $\overline{s^{2}+1.159 s+0.1815}$ \\
\hline \multirow[b]{2}{*}{6435} & \multirow[b]{2}{*}{10110} & \multirow[b]{2}{*}{12890} & 1 & \multirow[b]{2}{*}{4484} & \multirow[b]{2}{*}{9238} & \multirow[b]{2}{*}{13250} & 1 \\
\hline & & & $\overline{s^{2}+0.99 s+0.086}$ & & & & $\overline{s^{2}+1.383 s+0.403}$ \\
\hline \multirow[b]{2}{*}{203} & \multirow[b]{2}{*}{5341} & \multirow[b]{2}{*}{9319} & 1 & \multirow[b]{2}{*}{6268} & \multirow[b]{2}{*}{10230} & \multirow[b]{2}{*}{13530} & 1 \\
\hline & & & $\overline{s^{2}+1.25 s+0.27}$ & & & & $\overline{s^{2}+1.281 s+0.310}$ \\
\hline \multirow[b]{2}{*}{520} & \multirow[b]{2}{*}{6244} & \multirow[b]{2}{*}{10040} & 1 & \multirow[b]{2}{*}{194} & \multirow[b]{2}{*}{5599} & \multirow{2}{*}{10470} & 1 \\
\hline & & & $\overline{s^{2}+1.096 s+0.138}$ & & & & $\overline{s^{2}+1.175 s+0.175}$ \\
\hline \multirow[b]{2}{*}{502} & \multirow{2}{*}{6746} & \multirow{2}{*}{9589} & 1 & \multirow{2}{*}{233} & & & 1 \\
\hline & & & $\overline{s^{2}+1.19 s+0.27}$ & & 8256 & 8729 & $\overline{s^{2}+0.982 s+0.017}$ \\
\hline & 10610 & 14440 & 1 & 425 & 5825 & 10430 & 1 \\
\hline 7102 & 10610 & 14440 & $\overline{s^{2}+0.9128 s+0.0137}$ & 425 & 5825 & 10430 & $\overline{s^{2}+1.082 s+0.100}$ \\
\hline & & & 1 & & 0975 & & 1 \\
\hline 280 & 6923 & 10070 & $\overline{s^{2}+1.054 s+0.0110}$ & 5646 & 9975 & 14170 & $\overline{s^{2}+0.978 s+0.0137}$ \\
\hline & & & 1 & & & & 1 \\
\hline 5901 & 10230 & 12490 & $\overline{s^{2}+0.896 s+0.119}$ & 2467 & 9381 & 10440 & $\overline{s^{2}+1.279 s+0.297}$ \\
\hline & & & 1 & & & & 1 \\
\hline 594 & 5067 & 10150 & $\overline{s^{2}+1.21 s+0.26}$ & 92 & 6348 & 8783 & $\overline{s^{2}+1.218 s+0.238}$ \\
\hline & & & 1 & & & & 1 \\
\hline 8696 & 9279 & 12070 & $\overline{s^{2}+1.114 s+0.200}$ & 342.2 & 5685 & 10550 & $\overline{s^{2}+1.095 s+0.103}$ \\
\hline & & & 1 & & & & 1 \\
\hline 663 & 6301 & 9790 & $\overline{s^{2}+0.971 s+0.061}$ & 4185 & 10250 & 13800 & $\overline{s^{2}+1.019 s+0.039}$ \\
\hline & & & 1 & & & & 1 \\
\hline 6853 & 9709 & 14500 & $\overline{s^{2}+1.04 s+0.134}$ & 261 & 6991 & 10380 & $\overline{s^{2}+1.129 s+0.2553}$ \\
\hline & & & 1 & & & & 1 \\
\hline 7431 & 9635 & 12840 & $\overline{s^{2}+1.12 s+0.25}$ & 1633 & 9449 & 13180 & $\overline{s^{2}+1.458 s+0.4731}$ \\
\hline & & & 1 & & & & 1 \\
\hline 501 & 4469 & 9799 & $\overline{s^{2}+1.059 s+0.974}$ & 352 & 5760 & 10150 & $\overline{s^{2}+1.143 s+0.150}$ \\
\hline
\end{tabular}


Table 9. Continued

\begin{tabular}{|c|c|c|c|c|c|c|c|}
\hline \multicolumn{4}{|c|}{ Normal Subjects } & \multicolumn{4}{|c|}{ Parkinson(PD) Subjects } \\
\hline F1 & F2 & F3 & Transfer Function H(s) & F1 & F2 & F3 & Transfer Function H(s) \\
\hline \multirow{2}{*}{624} & \multirow{2}{*}{7309} & \multirow{2}{*}{10310} & 1 & \multirow{2}{*}{253} & \multirow{2}{*}{6247} & \multirow{2}{*}{8966} & 1 \\
\hline & & & $\overline{s^{2}+1.391 s+0.435}$ & & & & $\overline{s^{2}+1.167 s+0.217}$ \\
\hline \multirow{2}{*}{5918} & \multirow{2}{*}{11010} & \multirow{2}{*}{14140} & 1 & & & & \\
\hline & & & $\overline{s^{2}+0.841 s+0.088}$ & & & & \\
\hline \multirow{2}{*}{395} & \multirow{2}{*}{8573} & \multirow{2}{*}{9846} & 1 & & & & \\
\hline & & & $\overline{s^{2}+1.08 s+0.156}$ & & & & \\
\hline \multirow[t]{2}{*}{7287} & \multirow[t]{2}{*}{10720} & \multirow[t]{2}{*}{11290} & 1 & & & & \\
\hline & & & $\overline{s^{2}+1.136 s+0.1772}$ & & & & \\
\hline \multirow[t]{2}{*}{2715} & \multirow[t]{2}{*}{9805} & \multirow[t]{2}{*}{12270} & 1 & & & & \\
\hline & & & $\overline{s^{2}+1.268 s+0.3085}$ & & & & \\
\hline \multirow[t]{2}{*}{4694} & \multirow[t]{2}{*}{9725} & \multirow[t]{2}{*}{13520} & 1 & & & & \\
\hline & & & $\overline{s^{2}+1.143 s+0.172}$ & & & & \\
\hline \multirow[t]{2}{*}{6477} & \multirow[t]{2}{*}{10310} & \multirow[t]{2}{*}{13700} & 1 & & & & \\
\hline & & & $\overline{s^{2}+1.002 s+0.048}$ & & & & \\
\hline
\end{tabular}

Figure 6. Circuit for vocal tract filter

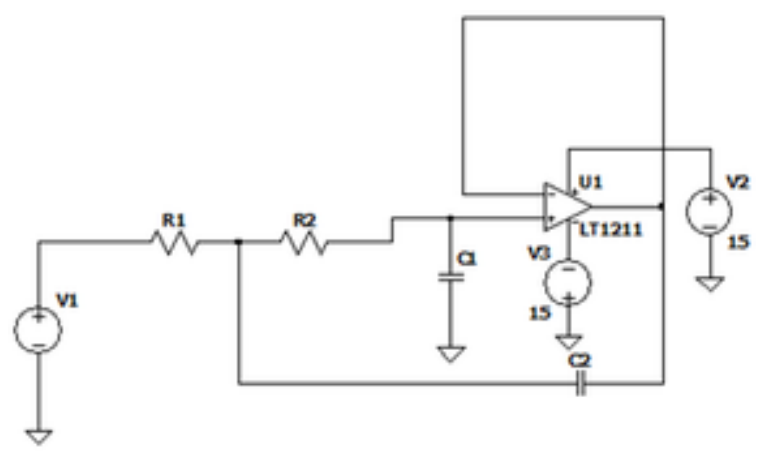




$$
\mathrm{H}(\mathrm{s})=\frac{\frac{1}{R^{2} C_{1} C_{2}}}{s^{2}+\left(\frac{2}{R C_{1}}\right) s+\frac{1}{R^{2} C_{1} C_{2}}}
$$

Comparing equations $4 \& 5$

$$
\mathrm{A}=\omega_{0}^{2}=\frac{1}{R^{2} C_{1} C_{2}}
$$

Consider, $\mathrm{R} 1=\mathrm{R} 2=\mathrm{R}$

$$
C_{1}=\frac{2 Q}{\omega_{0} R} \text { and } C_{2}=\frac{1}{2 \omega_{0} R Q}
$$

Table 10 shows all the computed values of components for each normalv. PD subject obtained from the circuit as given in Figure 6using equations 10,11 and 12.

Viewing the computed values in Table 11, it is clearthat in the case of most of PD subjects, the 3 - $\mathrm{dB}$ freuency is lower as compare to normal subjects. This means that the frequency response of the vocal tract filter is more stable at high values of frequency for normalsubjects.

\subsubsection{An Electrical Analogue of the Vocal Tract}

All speech sounds depend on the vocal tract configuration, glottal excitation and degree of coupling with the nasal tract. By making an electronic or electrical analogue of the vocal tract, it should be possible to synthesize its connected speech.

The vocal tract may be approximated as a cascade of short circular cylinders. The T-section electrical analogue for vocal tract is shown in Figure 7. The current (I) is analogous to volume velocity, inductances $(\mathrm{L} 1, \mathrm{~L} 2)$ are analogous to the inertance of air mass and capacitance(C) is analogous to the compliance of the air volume [33]. The resistance $(\mathrm{R})$ represents the power dissipated in viscous friction at the tube wall, and the conductance $(\mathrm{G})$ represents the power loss due to heat conduction at tube wall. Given that their values being small for the frequencies of interest, $(R)$ and $(G)$ may be neglected.

In the analogue, the glottis becomes a current source and current is given as:

$\mathrm{i}(\mathrm{t})=\mathrm{A}(\mathrm{t}) \sqrt{\frac{2 P_{s o}}{\rho}}$

Where,

$\mathrm{A}(\mathrm{t})$ is the area of glottal opening, Pso is mean value of sub-glottal pressure and $\rho$ is density of air.

The inductances are $L_{n}=\frac{\dot{A}_{n}}{2 \mathrm{kA}_{n}}$ and the capacitances are $C_{n}=\frac{\mathrm{kl}_{\mathrm{n}} \mathrm{A}_{\mathrm{n}}}{\mathrm{Ac}^{2}}$. The transmission line is terminated by $L_{r}=\frac{8 \dot{A}}{3 \grave{A}} \sqrt{\pi A_{n}}$ and $R_{r}=\frac{128 \hat{A}}{9 \pi^{2} A_{n}}$, where $A_{n}$ is the final (mouth) area. 
Table 10. Computed values of components of vocal tract filter circuit for each Normal and PD subject

\begin{tabular}{|c|c|c|c|c|c|c|c|c|c|}
\hline \multicolumn{5}{|c|}{ Normal Subjects } & \multicolumn{5}{|c|}{ Parkinson(PD) Subjects } \\
\hline R1(k) & R2(k) & C1(nf) & C2(nf) & $\begin{array}{c}3 \mathrm{~dB} \\
\text { Frequency(kHz) }\end{array}$ & R1(k) & R2(k) & C1(nf) & C2(nf) & $\begin{array}{c}3 \mathrm{~dB} \\
\text { Frequency }(\mathbf{k H z})\end{array}$ \\
\hline 10 & 10 & 1.8 & 1.8 & 5.6 & 10 & 10 & 4.7 & 9.8 & 2.4 \\
\hline 10 & 10 & .58 & 22 & 6.9 & 10 & 10 & 5.4 & 0.74 & 1.5 \\
\hline 10 & 10 & 1.9 & 2.2 & 5.6 & 10 & 10 & 1.9 & 2 & 5.4 \\
\hline 10 & 10 & 1.10 & 3.2 & 9.8 & 10 & 10 & 4.6 & 8 & 2.4 \\
\hline 10 & 10 & 1.5 & 1.6 & 6.9 & 10 & 10 & 5 & 73 & 1.2 \\
\hline 10 & 10 & 1.5 & 4.1 & 7.3 & 10 & 10 & 2.2 & 30 & 3.4 \\
\hline 10 & 10 & 1.5 & 0.25 & 5.5 & 10 & 10 & 1.6 & 32 & 3.3 \\
\hline 10 & 10 & 10 & 0.5 & 10.7 & 10 & 10 & 1.8 & 0.2 & 4.5 \\
\hline 10 & 10 & 1.4 & 1.7 & 7.2 & 10 & 10 & 1.5 & 0.57 & 5.7 \\
\hline 10 & 10 & 1.5 & 2.1 & 7.3 & 10 & 10 & 1.5 & 1.7 & 5 \\
\hline 10 & 10 & 2.08 & 6.6 & 6.2 & 10 & 10 & 1.4 & 1.6 & 7.4 \\
\hline 10 & 10 & 1.5 & 3.1 & 7.4 & 10 & 10 & 3.2 & 4 & 3.3 \\
\hline 10 & 10 & 1.4 & 1.7 & 7.6 & 10 & 10 & 3.1 & 4.1 & 3.5 \\
\hline 10 & 10 & 1.5 & 0.4 & 5.6 & 10 & 10 & 1.5 & 2.9 & 7.1 \\
\hline 10 & 10 & 1.3 & 1.1 & 7.6 & 10 & 10 & 1.5 & 9.8 & 5.7 \\
\hline 10 & 10 & 0.32 & 8.5 & 5.6 & & & & & \\
\hline 10 & 10 & 1.8 & 1.6 & 5.5 & & & & & \\
\hline 10 & 10 & 1.4 & 2.4 & 8 & & & & & \\
\hline 10 & 10 & 1.4 & 1.4 & 7.2 & & & & & \\
\hline 10 & 10 & 1.4 & 2.5 & 7.9 & & & & & \\
\hline 10 & 10 & 1.6 & 9 & 5.8 & & & & & \\
\hline
\end{tabular}

Table 11 shows the computed values of vocal tract length and area of each subject required for the computation of values of different components values of electrical equivalent of vocal tract.Figure 7. shows the equivent electrical circuit of the vocal tract. 
Table 11. computed values length and area of vocal tract

\begin{tabular}{|c|c|c|c|c|c|c|c|}
\hline \multicolumn{4}{|c|}{ Normal Subjects } & \multicolumn{4}{|c|}{ Parkinson(PD) Subjects } \\
\hline $\begin{array}{r}\mathbf{L 1}= \\
C\end{array}$ & $\begin{array}{r}\mathbf{L 2}=(\mathbf{c m}) \\
C F^{2}\end{array}$ & $\mathrm{A1}\left(\mathrm{cm}^{2}\right)$ & $\mathrm{A} 2\left(\mathrm{~cm}^{2}\right)$ & $\begin{array}{r}\mathrm{L} \mathbf{1}= \\
C\end{array}$ & $\begin{array}{l}\mathrm{L2}= \\
C F 2\end{array}$ & $\mathrm{~A} 1\left(\mathrm{~cm}^{2}\right)$ & $\mathrm{A} 2\left(\mathrm{~cm}^{2}\right)$ \\
\hline$\underset{(\mathbf{c m})}{2 F 2}$ & $20 \pi^{2} \boldsymbol{F} 1^{2}$ & & & $\underset{(\mathbf{c m})}{2 F 2}$ & $\underset{(\mathbf{c m})}{20 \pi^{2} F 1^{2}}$ & & \\
\hline 1.8 & 13.8 & 0.29 & 0.65 & 1.6 & 0.11 & 0.30 & 0.59 \\
\hline 1.7 & 0.04 & 0.31 & 0.59 & 1.9 & 0.08 & 0.55 & 0.52 \\
\hline 3.3 & 23.2 & 0.28 & 0.52 & 1.7 & 0.04 & 0.44 & 0.36 \\
\hline 2.8 & 4.1 & 0.48 & 0.41 & 3.1 & 26.6 & 0.43 & 0.69 \\
\hline 2.6 & 4.7 & 0.54 & 0.48 & 2.1 & 27.2 & 0.63 & 0.74 \\
\hline 1.6 & 0.03 & 1.6 & 1 & 3 & 5.7 & 1.2 & 1.05 \\
\hline 2.5 & 15.8 & 0.36 & 0.67 & 1.7 & 0.05 & 0.89 & 0.91 \\
\hline 1.7 & 0.05 & 0.87 & 0.87 & 1.8 & 0.27 & 0.60 & 0.81 \\
\hline 3.4 & 2.5 & 0.42 & 0.55 & 2.7 & 30.8 & 0.68 & 0.60 \\
\hline 1.9 & 0.02 & 0.56 & 0.75 & 3.1 & 8.7 & 10.2 & 2.4 \\
\hline 2.8 & 2.5 & 0.36 & 0.31 & 1.7 & 0.1 & 0.46 & 0.45 \\
\hline 1.8 & 0.03 & 0.20 & 0.18 & 2.5 & 18.3 & 0.21 & 0.40 \\
\hline 1.8 & 0.03 & 0.20 & 0.18 & 1.8 & 0.6 & 0.18 & 0.26 \\
\hline 3.9 & 3.1 & 0.62 & 0.69 & 3 & 8.3 & 0.65 & 0.62 \\
\hline 2.4 & 3.3 & 0.81 & 1.03 & 2.8 & 17.4 & 0.37 & 0.58 \\
\hline 1.6 & 0.05 & 0.43 & 0.60 & & & & \\
\hline 2.0 & 9.8 & 0.60 & 0.86 & & & & \\
\hline 1.6 & 0.03 & 0.63 & 0.63 & & & & \\
\hline 1.8 & 0.23 & 0.73 & 0.73 & & & & \\
\hline 1.8 & 0.04 & 0.60 & 0.67 & & & & \\
\hline 1.7 & 0.04 & 0.47 & 0.66 & & & & \\
\hline & & & & & & & \\
\hline & & & & & & & \\
\hline
\end{tabular}


Figure 7. Electrical Equivalent circuit of Vocal Tract

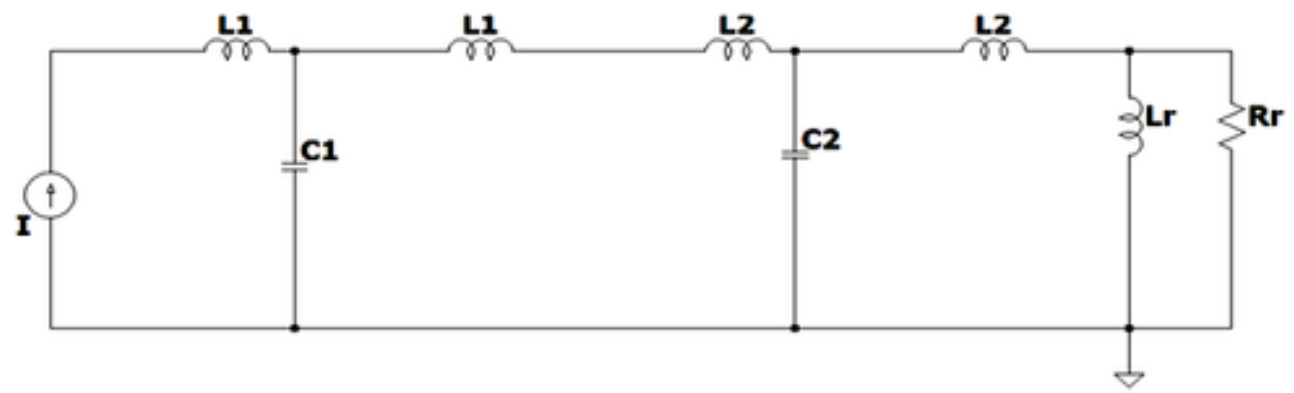

Table 12 shows the variation in component values of equivalent electrical circuit of the vocal tract for each normalv. PD subject.

Table 12. Computed values of all componets of equivalent electrical circuit for each subject

\begin{tabular}{|c|c|c|c|c|c|c|c|c|c|c|c|}
\hline \multicolumn{6}{|c|}{ Normal Subjects } & \multicolumn{6}{|c|}{ Parkinson's(PD) Subjects } \\
\hline L1 & L2 & C1 & C2 & $\mathbf{L r}$ & $\mathbf{R r}$ & L1 & L2 & C1 & $\mathrm{C2}$ & $\mathbf{L r}$ & $\mathbf{R r}$ \\
\hline 45.9 & 157 & 28 & 480 & 1.3 & 89 & 39.4 & 1.38 & 26 & 3.5 & 14 & 98 \\
\hline 40.5 & 0.50 & 28 & 1.27 & 1.3 & 98 & 25.5 & 1.13 & 57 & 2.2 & 4.4 & 111 \\
\hline 87.2 & 330 & 50 & 65 & 1.2 & 111 & 29.2 & 0.82 & 40 & 40 & 4.1 & 161 \\
\hline 43.1 & 74 & 72 & 91 & 1.0 & 141 & 53.3 & 285 & 72 & 994 & 5.1 & 84 \\
\hline 35.6 & 72.4 & 76 & 122 & 1.1 & 120 & 24.6 & 272 & 71 & 109 & 5.3 & 78 \\
\hline 7.4 & 0.22 & 138 & 1.6 & 1.7 & 58 & 18.5 & 40.1 & 195 & 324 & 6.3 & 55 \\
\hline 51.4 & 174 & 308 & 573 & 1.4 & 865 & 14.1 & 0.40 & 82 & 2.4 & 1.5 & 63 \\
\hline 14.4 & 0.42 & 80 & 2.3 & 1.6 & 67 & 22.2 & 2.4 & 58 & 11 & 5.5 & 72 \\
\hline 59.9 & 33.6 & 77 & 74 & 1.3 & 105 & 29.3 & 380 & 99 & 1.14 & 4.8 & 97 \\
\hline 25.1 & 5.8 & 77 & 813 & 1.5 & 77 & 2.2 & 26.8 & 171 & 1131 & 9.6 & 24 \\
\hline 57.5 & 0.32 & 42 & 42 & 95 & 187 & 27.3 & 1.64 & 42 & 86 & 4.1 & 128 \\
\hline 66.6 & 3.3 & 19 & 292 & 72 & 322 & 88.1 & 338 & 28 & 14 & 3.9 & 145 \\
\hline 66.6 & 3.3 & 19 & 292 & 1.4 & 322 & 74 & 17 & 17 & 8.4 & 3.1 & 223 \\
\hline 46.5 & 0.49 & 131 & 115 & 1.4 & 84 & 34.1 & 99 & 105 & 278 & 4.8 & 93 \\
\hline 21.9 & 1.1 & 105 & 184 & 4.7 & 56 & 56 & 222 & 56 & 547 & 4.7 & 100 \\
\hline 27.5 & 0.01 & 52 & 1.6 & 1.3 & 97 & & & & & & \\
\hline 24.6 & 99.3 & 65 & 456 & 1.6 & 67 & & & & & & \\
\hline 18.8 & 0.01 & 54 & 1.02 & 1.4 & 92 & & & & & & \\
\hline 18.2 & 0.09 & 70 & 9.1 & 1.5 & 79 & & & & & & \\
\hline 22.2 & 0.01 & 58 & 1.4 & 1.4 & 86 & & & & & & \\
\hline 26.7 & 0.01 & 43 & 1.4 & 1.4 & 88 & & & & & & \\
\hline
\end{tabular}




\section{CONCLUSION}

Altogether, the current work investigates the detection techniques using the voice signals for PD. It has been successfully experimented with an understanding that the acoustic parameters are more effective in PD detection to present 97.2\% accuracy with pitch/jitter ratio for the detection of Parkinson disease. As well, the authors argued for all pole filter model \&equivalent electrical model of vocal tract design for detecting voices. Synthesized vocal tract filter results shows that in the case of PD subjects, the 3-dB frequency response is lower as compared to normal subjects. It is remarkably concluded that changing values of the components of equivalent electrical model of vocal tract have proved equally effective in the detction of PD.

Notwithstanding, several limitations should be noted. First, although KCL Hospital database may be comprehensive in terms of the number of people being recorded; still, the gender imbalance in the dataset should be reconciled in future research to yield more reliable and meaningful results. Second, the quantity of data needed can be a challenge to this sort of research, requiring excessive computational power and simplification. Finally, we did not conduct our experiments separately on split subsets of data for the different genders, which may yield other interesting findings.

Future research will involve the collection of more data and improvements on the feature selection strategy sothat an objective analysis tool may be designed for clinical practice.As well, the detection of PD can be effectively improved with possible combination of emerging methodologies and technologies by performing sound analysis.

\section{ACKNOWLEDGMENT}

The authors are thankful to the Special Manpower Development Program, Chip-to-System Design (SMDP-C2SD), funded by the Ministry of Electronics \& Information Technology (MeitY), Govt. of India, as well as NIT kurukshetra for providing lab facilities in the School of VLSI Design and Embedded Systems. 


\section{REFERENCES}

Aarushi, A., Chandrayan, S., \& Sahu, S. S. (2016). Prediction of Parkinson's disease using speech signal with Extreme Learning Machine. International Conference on Electrical, Electronics, and Optimization Techniques (ICEEOT), 3776-3779.

Affonso, C., Rossi, A., Vieira, F., \& deCarvalho, A. (2017). Deep Learning for Biological Image Classification. Expert Systems with Applications, 85, 114-122. doi:10.1016/j.eswa.2017.05.039

Ali, Z., Elamvazuthi, I., Alsulaiman, M., \& Muhammad, G. (2016). Automatic Voice Pathology Detection with Running Speech by Using Estimation of Auditory Spectrum and Cepstral Coefficients Based on the All-Pole Model. Journal of Voice, 30(6), P757.E7-757.E19.

Alku, P. (2011). Glottal Inverse Filtering Analysis of Human Voice production-A Review of Estimation and Parameterization Methods of the Glottal Excitation and their Applications. Sadhana, 36(5), 623-650. doi:10.1007/ s12046-011-0041-5

Blumin, J. H., Pcolinsky, D. E., \& Atkins, J. P. (2004). Laryngeal Findings in Advanced Parkinson's Disease. The Annals of Otology, Rhinology, and Laryngology, 113(4), 253-258. doi:10.1177/000348940411300401 PMID:15112966

Chenausky, K., MacAuslan, J., \& Goldhor, R. (2011). Acoustic Analysis of PD Speech. Parkinson's Disease, 2011, 1-13. doi:10.4061/2011/435232 PMID:21977333

Dejonckere, P. H., \& Lebacq, J. (1984). Damping coefficient of oscillating vocal folds in relation with pitch perturbations. Speech Communication, 3(1), 89-92. doi:10.1016/0167-6393(84)90010-4

Diogo, B., Madureira, A. M., Luis, G., \& Ajith, R. (2019). Automatic deection of Parkinson's disease based on acoustic analysis of speech. Engineering Applications of Artificial Intelligence, 77, 148-158. doi:10.1016/j. engappai.2018.09.018

Dixit, M. V. \& Sharma, Y. (2014). Voice parameter analysis for disease detection. IOSR Journal of Electronics and Communication Engineering, 9, 48-55.

Drugman, T., Bozkurt, B., \& Dutoit, T. (2012). Comparative study of glottal source estimation techniques. Computer Speech \& Language, 26(1), 20-34. doi:10.1016/j.csl.2011.03.003

Fant, G., Liljencrants, J. \&Lin, Q. (1985). A four parameter model of glottal flow. STL-QPSR, 4, 1-13.

Ficko, M., Brezovnik, S., Klancnik, S., Balic, J., Brezocnik, M., \& Pahole, I. (2010). Intelligent Design of an Unconstrained Layout for a Flexible Manufacturing System. Neurocomputing, 73(4-6), 639-647. doi:10.1016/j. neucom.2009.06.019

Finkelhor, B. K., Titze, I. R., \& Durham, P. L. (1988). The effect of viscosity change in the vocal folds on the range of oscillation. Journal of Voice, 1(4), 320-325. doi:10.1016/S0892-1997(88)80005-5

Forero Mendoza LA, Cataldo E, Vellasco MM, Silva MA, \& Apolinário JA Jr. Classification of vocal aging using parameters extracted from the glottal signal. Journal of Voice: Official Journal of the Voice Foundation, 28(5),532-537.

Galaz, Z., Mekyska, J., Mzourek, Z., Smekal, Z., Rektorova, I., Eliasova, I., Kostalova, M., Mrackova, M., \& Berankova, D. (2016). Prosodic Analysis of Neutral, Stress-Modified and Rhymed Speech in Patients with Parkinson's Disease. Computer Methods and Programs in Biomedicine, 127, 301-317. doi:10.1016/j. cmpb.2015.12.011 PMID:26826900

Gupta, U., Bansal, H., \& Joshi, D. (2020). An improved sex-specific and age-dependent classification model for Parkinson's diagnosis using handwriting measurement. Computer Methods and Programs in Biomedicine. Advance online publication. doi:10.1016/j.cmpb.2019.105305

Ho, A. K., Iansek, R., Marigliani, C., Bradshaw, J. L., \& Gates, S. (1998). Speech impairment in a large sample of patients with Parkinson's disease. Behavioural Neurology, 11(3), 131-137. doi:10.1155/1999/327643 PMID:11568413 
Ho, A. K., Iansek, R., Marigliani, C., Bradshaw, J. L., \& Gates, S. (1999). Speech impairment in a large sample of patients with Parkinson's disease. Behavioural Neurology, 11(3), 131-137. doi:10.1155/1999/327643 PMID:22387592

Hrelja, M., Klancnik, S., Irgolic, T., Paulic, M., Balic, J., \& Brezocnik, M. (2013). Turning Parameters Optimization Using Particle Swarm Optimization. Proceedings of the 24th DAAAM International Symposium on Intelligent Manufacturing Automation, 670-677.

Ishizaka, K., \& Flanagan, J. L. (1972). Synthesis of voiced sounds from a two-mass model of the vocal cords. The Bell System Technical Journal, 51(6), 1233-1268. doi:10.1002/j.1538-7305.1972.tb02651.x

Lang, A. E., \& Lozano, A. M. (1998). Parkinson's disease. The New England Journal of Medicine, 339(15), 1044-1053. doi:10.1056/NEJM199810083391506 PMID:9761807

Lirani-Silva, C., Mourão, L. F., \& Gobbi, L. T. B. (2015). Dysarthria and Quality of Life in Neurologically Healthy Elderly and Patients with Parkinson's Disease. CoDAS, 27(3), 248-254. doi:10.1590/2317-1782/20152014083 PMID:26222941

Little, M. A., McSharry, P. E., Hunter, E. J., Spielman, J., \& Ramig, L. O. (2009). Suitability of dysphonia measurements for telemonitoring of Parkinson's disease, IEEE TransactionsBiomedical Engineering, 56, 10151022. Eng., 56, 1015-1022. doi:10.1109/TBME.2008.2005954 PMID:21399744

Liu, C. H., \& Xiong, W. (2015). Modelling and Simulation of Quality Risk Forecasting in a Supply Chain. International Journal of Simulation Modelling, 14(2), 359-370. doi:10.2507/IJSIMM14(2)CO10

Martens, H., Nuffelen, G., Wouters, K., \& Bodt, M. (2016). Reception of Communicative Functions of Prosody in Hypokinetic Dysarthria Due to Parkinson's Disease. Journal of Parkinson's Disease, 6(1), 219-229. doi:10.3233/ JPD-150678 PMID:26889630

Mittal, V., \& Sharma, R. K. (2019). Electrical Modeling of Two Tube Vocal Tract for voice pathology detection. Sensor Letters, 17, 943-946.

Mittal, V., \& Sharma, R. K. (2020). Voice Signal Analysis with the Application in Biomedicine. Sensor Letters, $18,122-127$.

Mohammad, S., Danial, F. T., \& Eshan, T. (2014). Speech analysis for diagnosis of Parkinson'sdisease using genetic algorithm and support vector machine. Journal of Biomedical Science and Engineering, 07, 147-156.

New, A. B., Robin, D. A., Parkinson, A. L., Eickhoff, C. R., Reetz, K., Hoffstaedter, F., Mathys, C., Sudmeyer, M., Grefkes, C., Larson, C. R., Ramig, L. O., Fox, P. T., \& Eickhoff, S. B. (2015). The intrinsic resting state voice network in Parkinson's disease. Human Brain Mapping, 36(5), 1951-1962.

Pawlukowska, W., Goła bb-Janowska, M., Safranow, K., Rotter, I., Amernik, K., Honczarenko, K., \& Nowacki, P. (2015). Articulation Disorders and Duration, Severity and L-Dopa Dosage in Idiopathic Parkinson's Disease. Neurologia i Neurochirurgia Polska, 49, 302-306.

Polat, K., \& Nour, M. (2020). Parkinson disease classification using one against all based data sampling with the acoustic features from the speech signals. Medical Hypotheses, 140, 1-6. doi:10.1016/j.mehy.2020.109678 PMID:32197120

Ramaker, C., Marinus, J., Stiggelbout, A. M., \& van Hilten, B. J. (2002). Systematic evaluation of rating scales for impairment and disability in Parkinson's disease. Movement Disorders, 17, 867-876.

Rusz, J., Bonnet, C., Klempiŕ, J., Tykalová, T., Baborová, E., Novotný, M., Rulseh, A., \& Růžička, E. (2015). Speech disorders reflect differing pathophysiology in Parkinson's disease, progressive supranuclear palsy and multiple system atrophy. Journal of Neurology, 262(4), 992-1001.

Sachin, S., Shukla, G., Goyal, V., Singh, S., Aggarwal, V., \& Behari, M. (2008). Clinical Speech Impairment in Parkinson's Disease, Progressive Supranuclear Palsy, and Multiple System Atrophy. Neurology India, 56, 122-126.

Saloni, Sharma, \& Gupta. (2016). Human Voice Waveform Analysis for Categorization of Normal and Parkinson Subjects. International Journal of Healthcare Information Systems and Informatics, 11, 21-35. 
Sapir, S. (2014). Multiple Factors Are Involved in the Dysarthria Associated with Parkinson's Disease: A Review With Implications for Clinical Practice and Research. Journal of Speech, Language, and Hearing Research: JSLHR, 57, 1330-1343.

Sarkar, , Isemkul Erdem, , \& Sarkar Okan, , Ahmet, Fikret, Sakir, Hulya \& Oclay. (2013). Collection and Analysis of a Parkinson Speech Dataset With Multiple Types of Sound Recordings. IEEE Journal of Biomedical and Health Informatics, 17, 828-834.

Saxena, M., Behari, M., Kumaran, S. S., Goyal, V., \& Narang, V. (2014). Assessing Speech Dysfunction Using BOLD and Acoustic Analysis in Parkinsonism. Parkinsonism \& Related Disorders, 20, 855-861.

Singh, N., Pillay, V., \& Choonara, Y. E. (2007). Advances in the treatment of Parkinson's disease. Progress in Neurobiology, 81, 29-44.

Tsanas, A. (2011). Novel speech signal processing algorithms for high-accuracy classification of Parkinson's. Retrieved from https://ieeexplore.ieee.org/iel5/10/4359967/06126094.pdf

Wee, K. H., Turichhia, L., \& Sarpeshkar, R. (2008). An Analog Integrated-Circuit Vocal Tract. IEEE Transactions on Biomedical Circuits and Systems, 2(4), 316-327.

Wee, K. H., Turichhia, L., \& Sarpeshkar, R. (2011). An Articulatory Vocal Tract for speech and hearing prostheses. IEEE Transactions on Biomedical Circuits and Systems, 5(4), 339-346.

Wei, Z., Chengzhi, Y., Qinghui, W., Fenglin, L., \& Ying, W. (2019). Classification of gait patterns between patients with Parkinson's disease and healthy controls usingphase space reconstruction (PSR), empirical mode decomposition (EMD) and neuralnetworks. Neural Networks, 111, 64-76.

Yao, X., \& Jissuhiro, T. (2013). Miyajima Chiyomi, Kitaoka Norihide \& Takeda,K.(2013). Classification of speech under stress based on modeling of the vocal folds and vocal tract. EURASIP Journal on Audio, Speech, and Music Processing, 17, 2-17.

Vikas Mittal received his M.Tech in Electronics and Communication Engineering from Kurukshetra University Kurukshetra. Currently, he is pursuing Ph.D. at National Institute of Technology (NIT) in the School of VLSI Design and Embedded Systems. His research interests include Biomedical Signal Processing, VLSI Design and Embedded System.

R. K. Sharma received his M. Tech in Electronics and Communication Engineering and PhD degree in Electronics and Communication Engineering from Kurukshetra University, Kurukshetra (through National Institute of Technology Kurukshetra), India in 1993 and 2007, respectively. Currently, he is a Professor with the Department of Electronics and Communication Engineering, NIT Kurukshetra, India. His main research interests are in the field of embedded applications, low power, digital design, and disease/ stress detections using voice profiling of human beings. 